\title{
Assessing prey selection of snow leopard in Mt. Kangchenjunga, Nepal
}

\author{
Kamal Thapa ${ }^{1}$, Natalie Schmitt ${ }^{2}$, Narendra Pradhan ${ }^{3}$, Hem Acharya ${ }^{4}$, and Santosh \\ Rayamajhi $^{1}$ \\ ${ }^{1}$ Tribhuvan University \\ ${ }^{2}$ McMaster University Faculty of Social Sciences \\ ${ }^{3}$ Affiliation not available \\ ${ }^{4}$ Government of Nepal Ministry of Forests and Soil Conservation
}

February 1, 2021

\begin{abstract}
In spring of 2012, we studied the feeding habits of snow leopard using a comprehensive approach that combines fecal genetic sampling, macro and microscopic analysis of snow leopard diets and direct observation of Naur and livestock in Kangchenjunga Conservation Area of east Nepal. Out of collected 88 putative snow leopard scat samples from 140 transects (290 km) in 27 ( $4 * 4 \mathrm{~km} 2)$ sampling grid cells, $83 \%$ were confirmed to be from snow leopard. The genetic analysis accounted for 19 individual snow leopards (10 male and 9 female) with a mean population size estimate of 24 (95\% CI: 19- 29), and an average density of 3.9 snow leopards $/ 100 \mathrm{~km} 2$ within $609 \mathrm{~km} 2$. Total available prey biomass of Naur and Yak was estimated at $355,236 \mathrm{~kg}(505$ $\mathrm{kg}$ yak $/ \mathrm{km} 2$ and $78 \mathrm{~kg} \mathrm{Naur} / \mathrm{km} 2$ ). From the available prey biomass, we estimated snow leopards consumed $7 \%$ annually which was comprised of wild prey (49\%), domestic livestock (45\%), and 6\% unidentified items. The estimated 47,736 kg Naur biomass gives a snow leopard-Naur ratio of 1: 59 on a weight basis. The proportion of young Naur was estimated at $17 \%$, with an almost double predation rate at $28 \%$. Predators such as common leopard and wolf share the same habitat and might compete with snow leopard for prey which will likely influence future predator-prey associations in KCA. Along with livestock insurance scheme improvement, there needs to be a focus on improved livestock guarding as well as engaging and educating local people to be citizen scientists on the importance of snow leopard conservation, involving them in long-term monitoring programs and promotion of ecotourism.
\end{abstract}

\section{Assessing prey selection of snow leopard in Mt. Kangchenjunga, Nepal}

Kamal Thapa, ${ }^{1}$ Tribhuvan University- Institute of Forestry, Kritipur, Kathmandu, Nepal

Natalie Schmitt, Department of Biochemistry and Biomedical Research, McMaster University, Canada

Narendra M. B. Pradhan, International Union for the Conservation of Nature (IUCN), Kathmandu, Nepal

Hem Raj Acharya, Department of National Parks and Wildlife Conservation, Babar Mahal, Kathmandu, Nepal

Santosh Rayamajhi, Tribhuvan University- Institute of Forestry, Kritipur, Kathmandu, Nepal

${ }^{1}$ Corresponding author's name: Kamal Thapa, Tribhuvan University- Institute of Forestry, Kritipur, Kathmandu, Nepal. Telephone (Mobile): 977 9840851551. Email:dreamerhimalaya@gmail.com

Abstract In spring of 2012, we studied the feeding habits of snow leopard using a comprehensive approach that combines fecal genetic sampling, macro and microscopic analysis of snow leopard diets and direct observation of Naur and livestock in Kangchenjunga Conservation Area of east Nepal. Out of collected 88 
putative snow leopard scat samples from 140 transects $(290 \mathrm{~km})$ in $27\left(4 * 4 \mathrm{~km}^{2}\right)$ sampling grid cells, $83 \%$ were confirmed to be from snow leopard. The genetic analysis accounted for 19 individual snow leopards (10 male and 9 female) with a mean population size estimate of 24 (95\% CI: 19- 29), and an average density of 3.9 snow leopards $/ 100 \mathrm{~km}^{2}$ within $609 \mathrm{~km}^{2}$. Total available prey biomass of Naur and Yak was estimated at $355,236 \mathrm{~kg}\left(505 \mathrm{~kg}\right.$ yak $/ \mathrm{km}^{2}$ and $78 \mathrm{~kg}$ Naur $\left./ \mathrm{km}^{2}\right)$. From the available prey biomass, we estimated snow leopards consumed $7 \%$ annually which was comprised of wild prey (49\%), domestic livestock (45\%), and $6 \%$ unidentified items. The estimated 47,736 kg Naur biomass gives a snow leopard-Naur ratio of 1: 59 on a weight basis. The proportion of young Naur was estimated at $17 \%$, with an almost double predation rate at $28 \%$. Predators such as common leopard and wolf share the same habitat and might compete with snow leopard for prey which will likely influence future predator-prey associations in KCA. Along with livestock insurance scheme improvement, there needs to be a focus on improved livestock guarding as well as engaging and educating local people to be citizen scientists on the importance of snow leopard conservation, involving them in long-term monitoring programs and promotion of ecotourism.

KEY WORDS common leopard, fecal, genetic analysis, naur, wolf, yak INTRODUCTION

Sustainable snow leopard conservation must necessarily involve the local people; however, it is becoming increasingly more difficult for humans and snow leopards to coexist peacefully in an increasingly human altered ecosystem (Ale et al., 2007; Jackson, 2015). Despite their abundant wild prey, snow leopard often kill livestock (Khanal et al., 2020; Jackson, 2015) as they are highly detectable and easy to capture (Lovari \& Mishra, 2016), but are often the primary livelihood source for many agropastoral communities. As a result, retaliatory killing of snow leopard by herders are common (Lovari \& Mishra, 2016; Jackson \& Lama, 2016; Ale et al., 2010) and practical solutions are becoming more challenging (GoN, 2012; Wegge et al., 2012; Ale et al., 2014). A key contributing factor to these continuing threats may be the difficulty in implementing conservation strategies (Ale et al., 2016) because of the lack of reliable information, both scientific and socio-economic (Jackson \& Lama, 2016). In Nepal or elsewhere, snow leopard is one of the poorly understood threatened species especially with respect to their distribution, home range, abundance, and feeding behavior (Wegge et al., 2012; Jackson et al., 2002). This is largely because snow leopard is sparsely distributed with low density in remote, highly rugged terrain (KCA, 2019) which can be logistically challenging and places constraints on methodology. As such, conservation planning and strategy in Nepal, especially for snow leopard, has been largely based on anecdotal evidence (DNPWC, 2017). 30 years ago, Oli (1993) conducted a detailed study on snow leopard diet, and subsequently by Wegge et al. (2012), where they predicted a sustainable predator-prey ratio with the presence of abundant small livestock breeds around Manang in the Annapurna Conservation Area (ACA) of west Nepal. However, unlike west Nepal, Lovari et al., 2009 reported that where small livestock breeds were not present in the Everest region, eastern Nepal, Himalayan tahr populations were becoming more suppressed as snow leopard were targeting young individuals preferentially. In Nepal, most studies on snow leopard status, their prey base and feeding behavior were concentrated around Dolpa in the west, Annapurna and Manslu in the Centre (Khanal et al., 2020; Shrestha et al., 2019; Chetri et al., 2019, 2017; Shrestha et al., 2018; Ale et al., 2014; Wegge et al., 2012; Thapa, 2005; Oli, 1994; Oli et al., 1993; Schaller, 1973) and around the Mt. Everest region in the east (Shrestha et al., 2018; Lovari \& Mishra, 2016; Lovari et al., 2013, 2009; Ale et al., 2007). However, no systematic study on snow leopard status, prey abundance and feeding behavior has been undertaken in the Kangchenjunga Conservation Area (KCA) in the far eastern region of Nepal, a critical snow leopard habitat to maintaining connectivity across the eastern snow leopard range and stands to suffer the greatest impact from climate change (MoFSC, 2017). Gurung et al. 2011 reported that snow leopard numbers had dramatically increased and there were no reports of retaliatory killing in the far east mainly because of successful implementation of community-managed livestock insurance.

A comprehensive understanding of the impact of snow leopard predation on wild ungulates and the role livestock play in their diet, is essential to devising strategy to reduce human- snow leopard conflicts. In the Mt. Kangchenjunga region, a human-altered mountain ecosystem in the far east of Nepal which is 
transboundary snow leopard habitat with India and China (KCA, 2019), we combine genetic sampling to estimate snow leopard abundance, both macro- and microscopic analysis to assess their diet, and an assessment of prey population dynamics. Based on comprehensive field data, we discuss status of snow leopard, abundance of wild prey and feeding behavior of snow leopards and recommend further conservation implications.

\section{MATERIALS AND METHODS}

\section{Study area}

KCA is part of the Taplejung District located in the far north-eastern part of Nepal. Bordering the state of Sikkim in India to the east and the Tibet Autonomous Region (TAR) of China to the north, the district $\left(20^{0}\right.$ $24^{\prime}-27^{0} 56^{\prime} \mathrm{N} \& 87^{0} 39^{\prime}-88^{0} 12^{\prime} \mathrm{E}$ ) covers mid-hills to high mountain terrains including Mt. Kangchenjunga $(8,586 \mathrm{~m})$, the world's third highest peak (Fig. 1). On 21 July, 1997, it was declared a conservation area spanning $2,035 \mathrm{~km}^{2}$. The climate is alpine and harsh in the upper parts, above 3,000 $\mathrm{m}$, and below this elevation, mixed temperate and sub-alpine climate is prevalent. The lower part of the study area receives snow fall for a few months and the upper range, heavy snow in winter every year. The topography is steep and rugged with mountainous terrain. The major fauna in KCA includes snow leopard, blue sheep Pseudois nayaur (here forth Naur), wolfCanis lupus, red fox Vulpes, pikas (Ochotona spp.), common leopard Panthera pardus, clouded leopard Neofelis nebulosa, red panda Ailurus fulgens, musk deer Moschus fuscus, and assamese monkey Macaca assamensis including many others (KCA, 2019; Thapa et al., 2013).

The study area comprises the headwaters of the Tamor River system and is characterized by rugged topography, with deep river canyons cutting through the lower reaches. Here rough boulder and scree-dominated hillsides intersperse alpine grasslands and meadows. Because of the abundant pastureland in the region, local people of upper Tamor have been practicing their livestock rearing for more than 150 years (Hooker, 1854). Yak, Dzo and cattle are common livestock kept for rearing in the area. Unlike western Nepal, domesticated small livestock are almost non-existence especially within snow leopard habitat.

\subsection{Survey design for snow leopard DNA sampling}

The study area of this project was selected based on the potential habitat of snow leopard, as outlined by WWF Nepal (2009). The altitudinal range of the study was chosen between 3000 and $5400 \mathrm{~m}$ (using a 1:50000 topographic map), consistent with the range both snow leopard and Naur have been detected across the Nepal Himalaya (Jackson \& Hunter, 1996).

The target study area included all suitable snow leopard habitat within the KCA. However, due to the immensity of this area, the steep terrain and numerous cliffs, it was not possible to cover all suitable habitat. Snow leopards are difficult to detect directly and are a wide-ranging species with an estimated annual home range of $1031.6 \mathrm{~km}^{2}$ for males and $470 \mathrm{~km}^{2}$ for female in the KCA (KCA, 2019). These estimates are significantly higher than home range estimates in other regions of Nepal such as the Longu valley and Manang (12 to $39 \mathrm{~km}^{2}$; Oli, 1997; Jackson \& Ahlborn, 1989) but comparable to Mongolia for females (up to 500 $\mathrm{km}^{2}$; Johansson et al., 2016; McCarthy et al., 2005). Because of the high variation in home range estimates, numerous sampling grids were used to divide up (each cell: $4^{*} 4 \mathrm{~km} ; 16 \mathrm{~km}^{2} ;$ Fig. 1) potential snow leopard habitat within the KCA. A relatively large survey cell was used to allow for areas that might be inaccessible. Multi-stage sampling (Janecka et al., 2011) was employed to ensure high interspersion of primary grids and more precise sampling cells (transects). Transects (following trail segment) were distributed within an altitudinal range of $4,195 \mathrm{~m}$ to $4,928 \mathrm{~m}$ in sites that were most likely to be visited by snow leopards, especially narrow ridgelines, cliff bases, passes, and the valley base at or immediately adjacent to frequently scent-sprayed rocks and scrape sites.

\subsection{Snow leopard scat collection}

From early April to mid-May (42 days) in 2012, 83 putative snow leopard scat samples were collected within 27 grids $\left(432 \mathrm{~km}^{2}\right)$ along the 140 transects $(290 \mathrm{~km})$. At least two transects each $1-1.5 \mathrm{~km}$ apart within each sampling grid was used following the technique used by Thapa, 2007 adopted from Jackson \& Hunter (1996). 
The length of transects was dependent on the terrain and human accessibility. To minimize collection of erroneous samples, scats were collected at snow leopard scrape sites and further discriminated by size and shape. A portion ( $\sim 1 \mathrm{CM}^{2}$; Janecka et al., 2011) of the collected scat samples were stored in $15 \mathrm{ml}$ vials with silica desiccant ( Janecka et al., 2008), labeled (with grid number, transect number, date, location, sample ID, GPS location etc.) and kept at room temperature prior to DNA analyses. Remaining portions of each sample were sun dried and put into paper envelopes for diet analysis.

\subsection{Molecular genetic analysis}

The collected samples were processed for identification of species, sex and individual. Genetic analyses (DNA extraction, species identification, sex identification, and individual identification) of putative snow leopard scat samples were conducted following the protocol developed by Karmacharya et al., 2011, adopted from Janecka et al. (2008).

\subsection{Population abundance and density estimation}

A free software program SPACECAP package version 3.0.2 (Gopalaswamy et al., 2012) was run to estimate snow leopard density from genetic samples; a user-friendly software package, implementing a Bayesian Spatially Explicit Capture Recapture (SECR) analysis (Royle et al., 2009). This software is recommended by Efford et al. (2009) for spatial CR data originating from different types of non-invasive sources, such as camera traps, hair snares or fecal DNA samples. SECR models in the SPACECAP package directly estimates animal density by explicitly using information on capture histories in combination with spatial locations of captures under a Bayesian modeling framework.

Following Singh et al. (2010), three types of input files were prepared to analyze data in the SPACECAP package: I. e. (i) Animal Capture Details, (ii) Trap Deployment Details and (iii) State-space Details. The trap deployment file consisted of trap location ID and spatial location of trap IDs in X and Y-coordinates (Universal Transverse Mercator UTM projection system) along with information on the occasions when each individual location was operational during the sample collection duration. Here the mid-center of grids was used as detectors (location) and we also reduced the number of sampling occasions by pooling the data together across three days due to a low encounter probability, as suggested by Janecka et al., 2011. The trap deployment data were organized in a two-dimensional matrix of individually identified locations and sampling occasions in a binary format (1s and 0s), indicating whether an individual location was or was not operational on a particular sampling occasion. A mesh of points (potential home range center) in each cell $\left(0.25 \mathrm{~km}^{2}\right)$ was generated using the Arc Geographical Information System (GIS) in a sampling array and 1.6 $\mathrm{km}$ buffer. The potential home range center file consisted of X and Y coordinates of all the potential activity centers in the UTM Projection System, and a habitat suitability indicator (using 1s or 0s) representing the potential activity centers within suitable or unsuitable habitat. The analysis was run in SPACECAP v 3.1 under the program R environment. For MCMC simulation, 60000 iterations were selected, 1000 burn in values (number of initial values to discard during the MCMC analysis) and 1 as thinning which was recommended by Royle et al. (2009). Only iteration numbers defined by the thinning rate are stored for the analysis (Singh et al., 2010). Since there was uncertainty about the total number of animals, which was likely to be larger than the minimum number identified during fecal DNA analysis, the value needed to be "augmented". Here fecal DNA analysis identified 19 individual snow leopards in this survey, thus data augmentation has been set at 100 as a rule thumb this was 5 times greater (Royle et al., 2009).

\subsection{Subsistence prey: naur and livestock}

Based on local knowledge and alleged dispersal barriers such as high peaks, deep gorges and glaciers, we divided the study area into four blocks (Fig.2) to survey naur and livestock within potential snow leopard habitat in the KCA. Each block was selected as follows:

1. Gola block; comprising the western border of Walangchung Gola and extending up to Tiptala in northern China, to the Nup Himalayan range in the east. 
2. Yagma block; comprising the Nup Himalayan range along with Khangla along the northern border of China, to Nanggola in the east.

3. Khambachen block; extending from Nanggola to the Jhonu Himalayan range in the east.

4. Ramjer block; extending from the Jhonu Himalayan range to Ratong La and Khang La along the eastern border of India.

In spring of 2012, we performed direct counts of Naur from appropriate vantage points (also known as a fixed-point count) within the four blocks of the KCA. The total number of individuals in a group was counted and classified by sex and age. To classify the sex and ages of Naur, a Snow Leopard Monitoring Guideline (Thapa, 2007) was utilized (adopted from Wegge, 1979). Observations were made with 8-24x binoculars and 15-60x spotting scope early in the morning (06.00am -10.00am) and afternoon (14.00pm-17.30pm) at Nepal Standard Time (NST) when Naur are known to be most active. Naur densities were estimated by dividing the total number of animals observed by the total area sampled within four blocks. Sampled area was obtained by adding up areas of all surveyed blocks. The area of each block was obtained by demarcating them on a GIS platform (i.e., Google Earth Program) post survey by the team of surveyors.

For domestic livestock information, opportunistic counting of livestock numbers was made in the pasture and consultation with key informants were used to verify the data obtained during the study.

\subsection{Food habits of snow leopard}

From known snow leopard scat samples derived from DNA analysis, a total of 73 collected scat samples were dried in the shade, labeled with a unique code and stored in an envelope for laboratory analyses. The samples were washed with tap water through a fine mesh sieve and oven-dried at a temperature of approximately $60^{\circ} \mathrm{C}$. Each sample was further cleaned in an ethanol- alcohol mixture (1:1).

Food items from scat samples were identified mainly from the macro- and microscopic structure of hairs. For this purpose, cuticular scale patterns of hairs were analyzed and further validated by medullary structure and cross-section (Koppikar \& Sabnis, 1976; Joslin, 1973). In order to compare hair samples with reference samples, reference images of available prey species from the study site were developed using microscopic images from a model B K Biological Trinocular Microscope (10x, 100x, 400x and 1000x) with DCM510 digital camera and further verified with reference samples developed by Oli (1993). For further accuracy, local reference samples were collected from each study site. Diet was analyzed through identification of 10 random hairs taken from each scat sample. Identification was further verified from the remains of bones, claws and hooves from prey species of interest also found within the scat samples. Remaining materials such as plants, rock, bones, and feathers were noted but not included in the analysis of diet. Results were expressed as the relative frequency of prey species found in the samples.

\subsubsection{Conversion of Prey Biomass}

An estimate of biomass consumed by snow leopard was used rather than occurrence percentage, as diet quantification may be more reliable (Wegge et al., 2012). Smaller animals, for example, are usually overrepresented in the scat analysis (Floyd et al., 1978). Frequency of occurrence of individual prey items are converted to biomass and numbers consumed according to the relationship between scat production and prey size (Ackerman et al., 1984; Floyd et al., 1978) in the following way: $\mathrm{Y}=1.980+0.035 \mathrm{X}$, where $\mathrm{Y}$ is weight of prey consumed per scat, and $\mathrm{X}$ is the live weight of particular prey (in $\mathrm{kg}$ ).

To quantify the predation rate of a snow leopard, average consumption rates per day of wild (Naur) and domestic livestock were used following Oli (1993) and Wegge, et al. (2012) as follows: Naur $34 \mathrm{~kg}$, Yak 150 $\mathrm{kg}$, horse $/$ cattle $140 \mathrm{~kg}$, goat $25 \mathrm{~kg}$, and sheep $30 \mathrm{~kg}$. Of large prey, predators did not consume the whole ungulate carcass due to inedible parts such as skeletal pieces, horns/antlers, rumen content and parts of the skin (Floyd et al., 1978). It was assumed that snow leopards consumed the following proportional weights of domestic and wild ungulate as described by Oli et al. (1993) and Wegge et al. (2012): Naur 75\%, yak 50\%, horse and cattle $60 \%$ and sheep and goat $70 \%$. 
A G-Test was employed to determine if snow leopard have a preference for certain species according to their availability across the study sites (Manly et al., 2007). To determine if particular species will be preferred, less preferred or avoided, a 95\% confidence interval was created for each category by applying Bonferroni corrections to the Z-statistic (Neu et al., 1974).

\section{Results}

\subsection{Snow Leopard Abundance}

Out of 88 putative samples, $73(83 \%)$ were confirmed by genetic analyses to be from snow leopard. Among snow leopard positive samples, 60\% (44) were successfully genotyped. Fecal DNA analysis identified 19 individual snow leopards (nine females and ten males) (Table 1; Fig. 2). GPS locations of individually identified snow leopards were plotted on digital topographic maps in ArcView 3.1 (Fig. 2) to calculate the survey area of sample collection. The mean maximum linear distance moved by individual snow leopards was calculated at $3.3 \mathrm{~km}$ (std. error 0.6) with a buffer strip width of $1.6 \mathrm{~km}$. The program SPACECAP estimated a mean snow leopard population size of 24 (95\% CI: 19-29; SD: 3.04). The mean density was 3.9 individuals/100 km² (95\% CI: 3.1- 4.8; SD: 0.8; Table 1) for the survey area of $609 \mathrm{~km}^{2}$. Khambachen block had a higher number of snow leopards, followed by Ramjer (eastern part of Khambachen), Yagma and Gola (both blocks lies north-western part of Khambachen).

The encounter probability was 1.73 (95\% CI: 0.21-1.19). Detection probability at trap locations was found to be 0.05 and the Psi, the ratio of the number of animals actually present within the space to the maximum allowable number, was 0.08. The number of effective alleles $\left(\mathrm{A}_{\mathrm{e}}\right)$ was 2.4 (se \pm 0.18$)$ and observed heterozygosity $\left(\mathrm{H}_{\mathrm{o}}\right)$ was 0.57 (se \pm 0.08 ) in six polymorphic loci.

\subsection{Available Biomass of Naur and Livestock}

Within the four blocks of the study area, a total of 45 Naur groups with 1404 individuals were counted and estimated density was $2.3 / \mathrm{km}^{2}$ (Table 2) in $609 \mathrm{~km}^{2}$. Recruitment was estimated to be 44 young per 100 adult females in the spring season. The mortality rate of yearlings was estimated to be $45 \%$, which could be consistent with a similar recruitment number in the previous year. Overall, the sex ratio was female-biased (73 males per 100 adult female).

In KCA, yaks (Dzo, Dee, Jhomo) dominated livestock types but small livestock like goat and sheep are negligible in the snow leopard habitat. Total estimated available standing biomass of yak was over six times greater compared to that of Naur (Table 3). The total number of Yak (2050) and Naur (1404) together accounted for $355,236 \mathrm{~kg}$ (Yak: $307,500 \mathrm{~kg}$ i.e. $505 \mathrm{~kg} / \mathrm{km}^{2}$ and Naur: $47,736 \mathrm{~kg}$ i.e. $78 \mathrm{~kg} / \mathrm{km}^{2}$ ) available standing biomass in the KCA.

\subsection{Snow leopard food habits}

Out of 73 snow leopard scat samples, micro-histological analysis revealed that one third of scats consisted of multiple prey and two thirds of single prey species. The prey consumed included three wild and four domestic mammals. Wild prey accounted for $49 \%$ whereas domestic prey accounted for $45 \%$, with the remainder unidentified, $6 \%$ ( $\mathrm{SD}=11.2 ; \mathrm{N}=8$; Table 4). Naur dominated wild prey in the snow leopard diet $(70 \%)$ $(\mathrm{SD}=3.1$ among total available wild prey species, $\mathrm{N}=3$ ) and yak was the dominant domestic prey item, accounting for approximately $43 \%$ of the total domestic livestock in the snow leopard diet, $(\mathrm{SD}=7.02, \mathrm{~N}=4)$.

The harvested biomass by one snow leopard per day was estimated at $3.7 \mathrm{~kg} /$ day (Table 5 ). This is equivalent to $1343 \mathrm{~kg}$ annually. This annual biomass estimate, in the KCA, would amount to 21 blue sheep, 2 musk deer, 318 pika, 2 yak, 0.5 cattle, 4 goats, 0.3 sheep and other small mammals including birds (Table 5). Snow leopard preferred Naur to yak, goat and sheep whereas they avoided cow and musk deer on prey biomass availability. Symbols $(-, 0,+)$ denote (Table 6) prey species that are avoided, less preferred, and more preferred respectively, according to their availability (based on 95\%, Bonferroni confidence intervals).

\subsection{Snow leopard-prey availability}


An annual food requirement for one snow leopard is $1343 \mathrm{~kg}$. Standing available food biomass of both wild and domestic livestock was calculated at $355,236 \mathrm{~kg}$. Naur, the snow leopard's staple food in the KCA, was calculated at 47, $736 \mathrm{~kg}$ and domestic yak, 307, $500 \mathrm{~kg}$. Harvesting rate of the estimated 24 snow leopards was about $7 \%$ per annum. If a snow leopard killed 21 Naur annually then the extant 24 snow leopards would require 504 Naur per annum. Without the biomass contribution of small mammals and livestock, the estimated available Naur biomass of 47, $736 \mathrm{~kg}$ gives a predator- prey ratio of 1:59 in KCA on a weight basis. Here in the KCA the proportion of young (Naur) is estimated at 17\%, but predation rate is almost double at $28 \%$.

\section{DISCUSSION}

The study estimated snow leopard density at $3.9 / 100 \mathrm{~km}^{2}(95 \% \mathrm{CI}=3.1-4.8$; SD: 0.8$)$ in the KCA. This estimate is lower than the densities recorded in the Phu valley by Wegge, et al., 2012 (6 individuals/125 $\mathrm{km}^{2}$ ), by Janecka et al., 2011 in Mongolia (5.9 individuals $/ 100 \mathrm{~km}^{2} ; 95 \% \mathrm{CI}=3.4-8.0$ ) and Oli, 1994 in Manang 4.8-6.7/100 $\mathrm{km}^{2}$. Jackson \& Ahlborn (1989) estimated 5-10 snow leopards/100 $\mathrm{km}^{2}$ in the prime habitat of the Langu valley and then extrapolated this estimate to a country-wide density of less than 0.10.5 snow leopards $/ 100 \mathrm{~km}^{2}$ in most parts of Nepal. The studies such as Jackson and Ahlborn (1989) and Oli (1997) which were based on expert opinion, sign evidence, VHF radio telemetry, and their extrapolations may be less reliable (McCarthy \& Chapron, 2003). Chetri et al. (2019) however, estimated a lower density of 1.07 individuals $/ 100 \mathrm{~km}^{2}$ (95\% CI: 0.71- 1.62) in Annapurna and 1.16 individuals $/ 100 \mathrm{~km}^{2}$ (95\% CI: 0.73- 1.87) in Manaslu of Nepal by modeling genetic sampling over a larger area. This lower density was likely due to Chetri et al. (2019) including the high mountain zone up-to $6000 \mathrm{~m}$ as potential snow leopard habitat in their study rather than the 3000-5400 m range considered (prime and fair) suitable snow leopard habitat in Nepal (Jackson \& Hunter, 1996). Recently, Khanal et al., 2020 estimated lower densities using remote camera traps compared to our estimates i.e., $2.51 / 100 \mathrm{~km}^{2}(95 \%$ CI: $1.36=4.60)$ in Upper Dolpa and 1.21/100 km² (95\% CI: 0.58-2.54) in Lower Dolpa of SPNP west Nepal. The estimated lower snow leopard density in western Nepal compared to the KCA could be a result of camera trap analysis from this study excluding sub-adult and young in density estimates.

Based on food requirements, 24 snow leopards would need an annual biomass of 32,232 $\mathrm{kg}$ in the KCA. Snow leopard diet in this study comprised both wild $(49 \%)$ and domestic $(45 \%)$ prey. Our estimates were consistent with that of Bagchi \& Mishra (2006) and Wegge et al. (2012), with 58\% and $42 \%$ livestock in India and Nepal respectively. Chetri et al., 2017 estimated 57\% of Naur and 31\% livestock in snow leopard diet within the Annapurna-Manaslu region, similar to the estimates of Lovari et al. (2013) and Ferretti et al. (2014) in the Mt Everest region (25\% livestock and 56\% Himalayan tahr). Within the Dolpa region of western Nepal however, Devkota et al., 2013 found that snow leopard diet consisted of only $30 \%$ Naur where marmot (buffer prey) and small livestock are plentiful. Oli (1994) stressed that snow leopards killed livestock because they are abundant and easy to kill compared to wild prey, not because they were a preferred food source. These findings are consistent with the results of our study in the KCA, particularly with the standing biomass of yak representing approximately $2 / 3$ of the total volume (with Naur occupying the other $1 / 3$ ).

Based on the estimate of Jackson \& Ahlborn (1989), that an adult snow leopard requires 20-30 Naur annually to survive, 24 snow leopards would need to consume 480-720 Naur per year. Jackson and Ahlborn (1989) hypothesized that a single snow leopard requires an estimated population of 150- 230 Naur to achieve this (possibly less in areas where other prey species are easily available). In the KCA snow leopards were estimated to harvest $28 \%$ of the Naur population annually, nearly twice the amount estimated (15.1\%) by Wegge et al. (2012) in the Phu valley, however the proportion of young Naur was found to be similar between the KCA and Phu (17\% compared to 18.4\%; Wegge et al., 2012). This difference could be explained by the greater availability of small livestock in the Phu Valley (Wegge et al., 2012; Thapa, 2005) compared to the KCA, providing snow leopards with a smaller prey target. The higher proportion of prey to predators around Manang (159:1; Oli, 1994) compared to KCA (59:1) could also explain this difference in Naur consumption. As well as the KCA having less "easy" small livestock prey available compared to Dolpa, Manang and the Phu Valley (Devkota et al., 2013; Wegge et al., 2012; Oli, 1994), snow leopards in the area also share habitat 
with two other apex predators, the common leopard along the forested- edge habitat in the south (Thapa et al., 2013) and grey wolf (Subba et al., 2017) in the north which will add significantly to the competitive pressures on Naur populations. Further long-term studies examining snow leopard, common leopard and wolf interactions are therefore needed.

The current situation indicates that available wild prey biomass is insufficient to support the estimated snow leopard population in the KCA. Therefore, livestock play an important role for the survival of snow leopard here in Nepal and elsewhere (Khanal et al., 2020; Mishra et al., 2016; Johansson et al., 2015; Sharma et al., 2015; Wegge et al., 2012; Shehzad et al., 2012; Oli et al., 1993). In most of the snow leopard's range, current community conservation initiatives focus on compensation and incentive, rather than preventative measures. Recently introduced Community- Managed Livestock Insurance Schemes in the KCA are offering huge promise for the long-term survival of snow leopards in the area by reducing the incentive for retribution killings (Gurung et al., 2011). However, financial compensation for livestock losses alone will not solve the problem (Thapa, 2006; Jackson, 2015). Along with this scheme improvement, there needs to be a focus on preventive measures such as improved livestock guarding as well as engaging and educating local people to be citizen scientists on the importance of snow leopard conservation, involving them in long-term monitoring programs and promotion of ecotourism.

ACKNOWLEDGEMENTS Permission was granted to conduct the study by the Department of National Parks and Wildlife Conservation (Ref.: 689/069/070). We are grateful to WWF International for awarding us the PRINCE BERNHARD scholarship (Grant no. 9Z0533.01) and WWF Nepal for the research grant to undertake this study. We also want to thank the Nepal Engineering College (nec-cps) especially the Director Prof. Dr. Khem Raj Sharma, Associate Prof. Dr. Narayan Kumar Shrestha, Associate Prof. Jhamak Bahadur Karki and Asst. Prof. Mr. Robert Dongol including Prof. Mukesh Kumar Chalishe (TU) for their guidance and critical review during drafting the paper.

Our sincere thanks go to members of the Snow Leopard Conservation Committees of KCA who collected the scat samples and also assisted us in gathering the Naur and domestic stock data in the field. We also acknowledge the Kangchenjunga Conservation Area Management Council and Kangchenjunga Conservation Area Project for mobilizing the Citizen Scientists who helped us gather reliable data from field. The team at the Center for Molecular Dynamics Nepal (CMDN) generously processed and analyzed our fecal samples in the lab. Finally, we are grateful to Mr. Gokarna Jung Thapa (GIS expert, WWF Nepal) for assisting us in preparing the map.

\section{Conflict Of Interest}

None.

\section{AUTHOR CONTRIBUTION}

Kamal Thapa: Study design, data collection, analysis and drafting and finalize.

Natalie Schmitt: Review and editing

Narendra Man Babu Pradhan: Study design, review.

Hem Raj Acharya: Study design and writing.

Santosh Rayamajhi: Review and edit.

\section{DATA ACCESSIBILITY}

The scat sample locations, DNA Sequences and Microsatellite Genotypes are available at the Dryad Digital Repository https://doi.org/10.5061/dryad.vq83bk3rn

\section{References}

Ackerman, B. B., Lindzey, F. G. \& Hemker, T. P. (1984). Cougar food habits in southern Utah. 
The Journal of Wildlife Management, pp.147-155.

Ale, S. B., Shah, K. B. \& Jackson, R.M. (2016). South Asia: Nepal. InSnow Leopards (pp. 471- 479). Academic Press.

Ale, S. B., Shrestha, B. \& Jackson, R. (2014). On the status of snow leopard Panthera uncia (Schreber, 1775) in Annapurna, Nepal. Journal of Threatened Taxa, 6 (3), pp.5534-5543.

Ale, S. B., Thapa, K., Jackson, R. \& Smith, James, I. D. (2010). The fate of snow leopards in and around Mt. Everest. Cat News . 53. pp. 19-21.

Ale, S. B., Yonzon, P. \& Thapa, K. (2007). Recovery of snow leopard Uncia uncia in Sagarmatha (Mount Everest) National Park, Nepal. Oryx , 41(1), pp.89-92.

Bagchi, S. \& Mishra, C. (2006). Living with large carnivores: predation on livestock by the snow leopard (Uncia uncia ). Journal of zoology , 268 (3), pp.217-224.

Chetri, M., Odden, M., Sharma, K., Flagstad, Ø. \& Wegge, P. (2019). Estimating snow leopard density using fecal DNA in a large landscape in north-central Nepal.

Global ecology and conservation, 17 , p.e00548.

Chetri, M., Odden, M. \& Wegge, P. (2017). Snow leopard and Himalayan wolf: food habits and prey selection in the Central Himalayas, Nepal. PloS one, 12(2).

Devkota, B. P., Silwal, T. \& Kolejka, J. (2013). Prey density and diet of snow leopard (Uncia uncia) in Shey Phoksundo National Park, Nepal. Applied Ecology and Environmental Sciences, 1(4), pp.5560.

DNPWC. (2017). The Snow Leopard Conservation Action Plan for Nepal (2017- 2021).

Department of National Parks and Wildlife Conservation, Kathmandu, Nepal.

Efford, M. G., Dawson, D. K. \& Borchers, D. L. (2009). Population density estimated from locations of individuals on a passive detector array. Ecology, 90(10), pp.2676-2682.

Ferretti, F., Lovari, S., Minder, I. \& Pellizzi, B. (2014). Recovery of the snow leopard in Sagarmatha (Mt. Everest) National Park: effects on main prey.European journal of wildlife research, 60(3), pp.559-562.

Floyd, T. J., Mech, L.D. \& Jordan, P.A. (1978). Relating wolf scat content to prey consumed.

The Journal of Wildlife Management, pp.528-532.

Gopalaswamy, A.M., Royle, J. A., Hines, J. E., Singh, P., Jathanna, D., Kumar, N. S. \&

Karanth, K. U. (2012). Program SPACECAP: software for estimating animal density using spatially explicit capture-recapture models.Methods in Ecology and Evolution, 3(6), pp.1067- 1072.

GoN. (2012). The Snow Leopard Conservation Action Plan for Nepal (2005- 2015, Revised 2012). 1st ed. Kathmandu: Department of National Parks and Wildlife Conservation, Nepal.

Gurung, G. S., Thapa, K., Kunkel, K., Thapa, G.J., Kollmair, M. \& Müller-Böker, U. (2011). 
Enhancing herders' livelihood and conserving the snow leopard in Nepal.Cat News, 55, pp.17- 21.

Hooker, J. D. (1854). Notes of a naturalist in Bengal, the Sikkim and Nepal Himalayas, the

Khasia Mountains, \&3 c. Himalayan Journals , 1, pp.1-408.

Jackson, R. M. \& Lama, W. B. (2016). The role of mountain communities in snow leopard conservation. In Snow Leopards (pp. 139-149). Academic Press.

Jackson, R. M. (2015). HWC ten years later: Successes and shortcomings of approaches to global snow leopard conservation. Human Dimensions of Wildlife ,20 (4), pp.310-316.

Jackson, R.M., Wangchuk, R. \& Hillard, D. (2002). Grassroots measures to protect the endangered snow leopard from herder retribution: Lessons learned from predator proofing corrals in Ladakh. - International Snow Leopard Trust, Seattle, Washington, USA, pp. 104-117.

Jackson, R. M. \& Hunter, D. O. (1996). Snow Leopard Survey and Conservation Handbook . International Snow Leopard Trust. USA.

Jackson, R. \& Ahlborn, G. (1989). Snow leopards (Panthera uncia) in Nepal: home range and movements. National Geographic Research , 5 (2), pp.161-175.

Janečka, J. E., Munkhtsog, B., Jackson, R. M., Naranbaatar, G., Mallon, D. P. \& Murphy, W. J.

(2011). Comparison of noninvasive genetic and camera-trapping techniques for surveying snow leopards. Journal of Mammalogy, 92(4), pp.771-783.

Janecka, J. E., Jackson, R., Yuquang, Z., Diqiang, L., Munkhtsog, B., Buckley-Beason, V. \&

Murphy, W. J. (2008). Population monitoring of snow leopards using noninvasive

collection of scat samples: a pilot study. Animal Conservation ,11 (5), pp.401-411.

Johansson, Ö., Rauset, G.R., Samelius, G., McCarthy, T., Andrén, H., Tumursukh, L. \&

Mishra, C. (2016). Land sharing is essential for snow leopard conservation. Biological Conservation, 203, pp.1-7.

Johansson, Ö., McCarthy, T., Samelius, G., Andrén, H., Tumursukh, L. \& Mishra, C. (2015).

Snow leopard predation in a livestock dominated landscape in Mongolia.

Biological

Conservation, 184, pp.251-258.

Joslin, P. (1973). The Asiatic lion: a study of ecology and behaviour. A thesis presented for the degree of Doctor of Philosophy in the Department of Forestry and Natural Resources, University of Edinburgh.

KCA. (2019). Satellite telemetry on snow leopards in Kangchenjunga Conservation Area.

Kangchenjunga Conservation Area Office, Faktalung- 6, Taplejung.

Karmacharya, D. B., Thapa, K., Shrestha, R., Dhakal, M. \& Janecka, J. E. (2011). Noninvasive

genetic population survey of snow leopards (Panthera uncia) in Kangchenjunga Conservation Area, Shey Phoksundo National Park and surrounding buffer zones of Nepal. BMC research notes,4(1), p.516.

Khanal, G., Mishra, C. \& Suryawanshi, K. R. (2020). Relative influence of wild prey and livestock 
abundance on carnivore-caused livestock predation. Ecol. Evol.2020;00:1-11. https://doi.org/10.1002/ece3.6815

Koppikar, B. R. \& Sabnis, J. H. (1976). Identification of hairs of some Indian mammals. J.

Bombay Nat. Hist. Soc, 73 (1), pp.5-20.

Lovari, S. \& Mishra, C. (2016). Living on the edge: depletion of wild prey and survival of the snow leopard. In Snow Leopards (pp. 69-76). Academic Press.

Lovari, S., Minder, I., Ferretti, F., Mucci, N., Randi, E., \& Pellizzi, B. (2013). Common and snow

leopards share prey, but not habitats: competition avoidance by large predators? Journal of Zoology, 291(2), $127-135$.

Lovari, S., Boesi, R., Minder, I., Mucci, N., Randi, E., Dematteis, A. \& Ale, S.B. (2009). Restoring

a keystone predator may endanger a prey species in a human-altered ecosystem: the return of the snow leopard to Sagarmatha National Park.Animal Conservation 12(6), pp.559-570.

Manly, B.F.L., McDonald, L., Thomas, D. L., McDonald, T. L. and Erickson, W.P. (2007).

Resource selection by animals: statistical design and analysis for field studies. Springer Science \& Business Media.

McCarthy, T. M., Fuller, T. K. \& Munkhtsog, B. (2005). Movements and activities of snow leopards in Southwestern Mongolia. Biological Conservation, 124(4), pp.527-537.

McCarthy, T. M. \& Chapron, G. (2003). Snow Leopard Survival Strategy. ISLT and SLN, Seattle, USA.

Mishra, C., Redpath, S. R. \& Suryawanshi, K. R. (2016). Livestock predation by snow leopards: conflicts and the search for solutions. In Snow leopards (pp. 59-67). Academic Press.

MoFSC. (2017). Snow Leopard and Ecosystem Management Plan (2017-2026). Ministry of Forests and Soil Conservation, Kathmandu, Nepal.

Neu, C. W., Byers, C. R. \& Peek, J. M. (1974). A technique for analysis of utilization-availability data. The Journal of Wildlife Management:541-545.

Oli, M. K. (1997). Winter home range of snow leopards in Nepal.MAMMALIA-PARIS -, 61, pp.355-360.

Oli, M.K. (1994). Snow leopards and blue sheep in Nepal: densities and predator: prey ratio. Journal of Mammalogy , 75(4), 998-1004.

Oli, M.K. (1993). A key for the identification of the hair of mammals of a snow leopard (Panthera uncia) habitat in Nepal. Journal of Zoology, 231(1), pp.71-93.

Oli, M. K., Taylor, I. R. \& Rogers, D. M. (1993). Diet of the snow leopard (Panthera uncia) in the Annapurna Conservation Area, Nepal. Journal of Zoology, 231(3), pp.365-370.

Royle, J. A., Karanth, K. U., Gopalaswamy A. M. \& Kumar, N. S. (2009). Bayesian inference in camera trapping studies for a class of spatial capture-recapture models. Ecology, 90(11), pp.3233-3244. Schaller, G. B. (1973). On the behavior of blue sheep (Pseudois nayaur ). Journal of the 
Bombay Natural History Society, 69, 523-537.

Sharma, R. K., Bhatnagar Y. V. \& Mishra. C. (2015). Does livestock benefit or harm snow

leopards? Biological Conservation , 190, pp.8-13.

Shehzad, W., McCarthy, T. M., Pompanon, F., Purevjav, L., Coissac, E., Riaz, T. \&

Taberlet, P. (2012). Prey preference of snow leopard (Panthera uncia) in South Gobi, Mongolia. PloS one, $7(2)$.

Shrestha, A., Thapa, K., Subba, S.A., Dhakal, M., Devkota, B.P., Thapa, G.J., Shrestha, S., Malla,

S. and Thapa, K. (2019). Cats, canines, and coexistence: dietary differentiation between the sympatric Snow Leopard and Grey Wolf in the western landscape of Nepal Himalaya. Journal of Threatened Taxa, 11(7), pp.13815-13821.

Shrestha, B., Aihartza, J., \& Kindlmann, P. (2018). Diet and prey selection by snow leopards in the Nepalese Himalayas. PLoS One, 13 (12), e0206310.

Singh, P., A., Gopalaswamy, M. A. Royle, J., Samba, N. K. \& Karanth, K. U. (2010).

SPACECAP: A Program to Estimate Animal Abundance and Density using Bayesian Spatially- Explicit Capture-Recapture Models. Wildlife Conservation Society - India Program, Centre for Wildlife Studies, Bangalure, India. Version 1.0.

Subba, S., Shrestha, A., Thapa, K., Malla, S., Thapa, G., Shrestha, S., Shrestha, S., Subedi, N.,

Bhattarai, G. P. \& Ottvall, R. (2017). Distribution of grey wolves Canis lupus lupus in the Nepalese Himalaya: Implications for conservation management. Oryx, 51(3), 403-406. doi:10.1017/S0030605316000296

Thapa, K., Pradhan, N. B., Barker, J., Dhakal, M., Bhandari, A. R., Gurung, G. S., Rai, D. P.,

Thapa, G. J., Shrestha, S. \& Singh, G.R. (2013). High elevation records of a leopard cat in the Kangchenjunga Conservation Area, Nepal.Cat News, 58, pp.26-27.

Thapa, K. (2007). Snow Leopard Monitoring Guideline . Kathmandu: WWF Nepal.

Thapa. K. (2006). Study on status and distribution of snow leopard and blue sheep including

people interaction: A Case Study from Kangchenjunga Conservation Area, Taplejung and Shey- Pkhoksundo National Park. Unpublished Report. WWF Nepal Program, Kathmandu, Nepal.

Thapa, K. (2005). Is there any correlation between abundance of blue sheep population and

livestock depredation by snow leopards in the Phu Valley, Manang District, Annapurna

Conservation Area? International Snow Leopard Trust, Snow Leopard Network, USA.

Wegge, P., Shrestha, R. \& Flagstad, O. (2012). Snow leopardPanthera uncia predation on

livestock and wild prey in a mountain valley in northern Nepal: implications for conservation management. Wildlife Biology, 18(2), pp.131-141.

Wegge, P. (1979). Aspects of the population ecology of blue sheep in Nepal. Journal of Asian

Ecology, 1, pp.10-20.

WWF Nepal. (2009). Estimating snow leopard populations in the Nepal Himalaya. Unpublished report. WWF Nepal, Kathmandu, Nepal.

Figure 1. Study area location within prime snow leopard habitat in the Kangchenjunga Conservation Area, northern Nepal where we conducted snow leopard scat collection and Naur and livestock surveys during 
Spring (April-May) 2012. Blue dots denote putative snow leopard scat collection sites in the sampling grids $\left(4^{*} 4 \mathrm{~km}^{2}\right)$.

Figure 2. Location points of individual snow leopard identified by fecal DNA analysis within the four major blocks of potential snow leopard habitat (Ramjer, Khambachen, Yagma and Gola) of the KCA during the Spring Season (April- May) 2012.

Table 1. Summary of Model Parameters for Snow Leopard Fecal DNA analysis from the KCA, 2012. (Bayesian p-value based on individual encounters: 0.75); Sigma- Encounter probability, Lamda- Detection probability at trap location that considered home range, Psi- Data augmentation parameter (the ratio of the number of animals actually presents within $\mathrm{S}$ to the maximum allowable number), Nsuper- Population size, and Density- Animals per $100 \mathrm{~km}^{2}$ ).

\begin{tabular}{lllll}
\hline Item & Mean & SD & CI 95\% (Lower Level) & CI 95\% (Upper Level) \\
\hline Sigma & 1.73 & 3.23 & 0.21 & 1.19 \\
lam0 & 0.05 & 0.09 & 0.03 & 0.06 \\
Psi & 0.08 & 0.02 & 0.04 & 0.11 \\
Nsuper & 23.57 & 3.04 & 19 & 29 \\
Density & 3.9 & 0.8 & 3.1 & 4.8 \\
\hline
\end{tabular}

Table 2. Demographic Population Structure of Naur in the KCA, 2012. Table describes sex and age of Naur within each sampling block. The Group category gives the total number of Naur individuals within the sampling block, $\mathrm{FE}=$ the number of Adult Females (more than 2 years), $\mathrm{YO}=$ the number of Young (below one year age of both male and female), $\mathrm{YE}=$ the number of Yearlings (in between one and two year ages of both male and female), YM = the number of Young Males (above two and below four years), MM = the number of Middle Males (above five and below seven years), BM = the number of Big Males (above seven years) and UI $=$ the number of those Unidentified (all ages both male and female) Thapa, 2007 adopted from Wegge, 1979.

\begin{tabular}{llllllllll}
\hline Block & Group & FE & YO & YE & YM & MM & MM & UI & Total \\
\hline Ramjer & 4 & 42 & 20 & 7 & 10 & 5 & 5 & 15 & 104 \\
Khambachen & 17 & 267 & 99 & 37 & 37 & 78 & 89 & 27 & 634 \\
Yagma & 16 & 177 & 82 & 64 & 50 & 43 & 41 & 53 & 510 \\
Gola & 8 & 54 & 34 & 21 & 15 & 13 & 8 & 11 & 156 \\
Total & 45 & 540 & 235 & 129 & 112 & 139 & 143 & 106 & 1404 \\
\hline
\end{tabular}

Table 3. Available Standing Biomass of Yak and Naur in the KCA, 2012. We assume an average weight of $150 \mathrm{~kg}$ for a yak and an average weight of $34 \mathrm{~kg}$ for a Naur (adopted from Wegge et al., 2012).

\begin{tabular}{lllll}
\hline Block & No. of Yak & Biomass $(\mathrm{kg})$ & No. of Naur & Biomass $(\mathrm{kg})$ \\
\hline Gola & 459 & 68,850 & 156 & 5,304 \\
Yagma & 601 & 90,150 & 510 & 17,340 \\
Khambachen & 804 & 120,600 & 634 & 21,556 \\
Ramjer & 186 & 27,900 & 104 & 3,536 \\
Total & 2,050 & 307,500 & 1,404 & 47,736 \\
\hline
\end{tabular}

Table 4. Count and Frequency of Prey Items in the Snow Leopard Diet From Microscopic Analysis of Fecal 
Material in the KCA ( $\mathrm{n}=73), 2012$.

\begin{tabular}{lll}
\hline Prey Species & Count & $\%$ of Frequency \\
\hline Naur & 70 & 34.3 \\
Musk deer & 11 & 5.4 \\
Pika & 19 & 9.3 \\
Yak & 40 & 20 \\
Cow & 7 & 3 \\
Goat & 35 & 17 \\
Sheep & 10 & 5 \\
Unidentified & 12 & 6 \\
Total & 204 & 100 \\
\hline
\end{tabular}

Table 5. Estimation of Prey Species Consumed in a Year by a Snow Leopard in the KCA, 2012. A= assumed weight of the prey species; $\mathrm{B}=\mathrm{Y}$ (i.e. $\mathrm{Y}=1.98+0.035^{*} \mathrm{~A}$ ); $\mathrm{C}=$ Frequency of occurrence in scats; $\mathrm{D}=$ Biomass consumed $\left(\mathrm{B}^{*} \mathrm{C}\right) ; \mathrm{E}=$ Biomass eaten by a snow leopard assuming a rate of $3.7 \mathrm{~kg} /$ day; $\mathrm{F}=$ No. of prey species consumed by a snow leopard/ year based on E divided by A.

\begin{tabular}{lll}
\hline Prey Species & Estimated mass $(\mathrm{A})$ & Biomass/scat $(\mathrm{B}) \mathrm{c}$ \\
\hline Blue sheep & 34 & 3.17 \\
Musk deer & 16.5 & 2.56 \\
Pika & 0.3 & 1.99 \\
Yak & 150 & 7.23 \\
Cow & 140 & 6.88 \\
Goat & 25 & 2.86 \\
Sheep & 30 & 3.03 \\
Others & 2 & 2.05 \\
Biomass $(\mathrm{KG})$ consumed by a snow leopard/year & Biomass $(\mathrm{KG})$ consumed by a snow leopard/year & Biomass (KG) consu \\
\hline
\end{tabular}

\begin{tabular}{|c|c|c|c|c|c|c|}
\hline $\begin{array}{l}\text { Table } 6 . \\
\text { Utilization, } \\
\text { Availability } \\
\text { and }\end{array}$ & $\begin{array}{l}\text { Table } 6 . \\
\text { Utilization, } \\
\text { Availability } \\
\text { and }\end{array}$ & $\begin{array}{l}\text { Table } 6 . \\
\text { Utilization, } \\
\text { Availability } \\
\text { and }\end{array}$ & $\begin{array}{l}\text { Table } 6 . \\
\text { Utilization, } \\
\text { Availability } \\
\text { and }\end{array}$ & $\begin{array}{l}\text { Table } 6 . \\
\text { Utilization, } \\
\text { Availability } \\
\text { and }\end{array}$ & $\begin{array}{l}\text { Table } 6 . \\
\text { Utilization, } \\
\text { Availability } \\
\text { and }\end{array}$ & $\begin{array}{l}\text { Table } 6 . \\
\text { Utilization, } \\
\text { Availability } \\
\text { and }\end{array}$ \\
\hline $\begin{array}{l}\text { Preference } \\
\text { of Prey }\end{array}$ & $\begin{array}{l}\text { Preference } \\
\text { of Prey }\end{array}$ & $\begin{array}{l}\text { Preference } \\
\text { of Prey }\end{array}$ & $\begin{array}{l}\text { Preference } \\
\text { of Prey }\end{array}$ & $\begin{array}{l}\text { Preference } \\
\text { of Prey }\end{array}$ & $\begin{array}{l}\text { Preference } \\
\text { of Prey }\end{array}$ & $\begin{array}{l}\text { Preference } \\
\text { of Prey }\end{array}$ \\
\hline $\begin{array}{l}\text { Species in } \\
\text { Snow }\end{array}$ & $\begin{array}{l}\text { Species in } \\
\text { Snow }\end{array}$ & $\begin{array}{l}\text { Species in } \\
\text { Snow }\end{array}$ & $\begin{array}{l}\text { Species in } \\
\text { Snow }\end{array}$ & $\begin{array}{l}\text { Species in } \\
\text { Snow }\end{array}$ & $\begin{array}{l}\text { Species in } \\
\text { Snow }\end{array}$ & $\begin{array}{l}\text { Species in } \\
\text { Snow }\end{array}$ \\
\hline Leopard & Leopard & Leopard & Leopard & Leopard & Leopard & Leopard \\
\hline $\begin{array}{l}\text { Diet within } \\
\text { the KCA } \\
(2012) \text {. }\end{array}$ & $\begin{array}{l}\text { Diet within } \\
\text { the KCA } \\
(2012) \text {. }\end{array}$ & $\begin{array}{l}\text { Diet within } \\
\text { the KCA } \\
(2012) \text {. }\end{array}$ & $\begin{array}{l}\text { Diet within } \\
\text { the KCA } \\
(2012) \text {. }\end{array}$ & $\begin{array}{l}\text { Diet within } \\
\text { the KCA } \\
(2012) \text {. }\end{array}$ & $\begin{array}{l}\text { Diet within } \\
\text { the KCA } \\
(2012) \text {. }\end{array}$ & $\begin{array}{l}\text { Diet within } \\
\text { the KCA } \\
(2012) \text {. }\end{array}$ \\
\hline Species & Utilization & Utilization & Availability & $\begin{array}{l}90 \% \\
\text { Bonferroni } \\
\text { confidence } \\
\text { interval }\end{array}$ & $\begin{array}{l}90 \% \\
\text { Bonferroni } \\
\text { confidence } \\
\text { interval }\end{array}$ & Preference \\
\hline & Counts & Proportion & Proportion & Lower & Upper & \\
\hline Blue sheep & 70 & 0.40 & 0.07 & 0.38 & 0.44 & + \\
\hline Musk deer & 11 & 0.05 & 0.06 & 0.02 & 0.04 & - \\
\hline
\end{tabular}




\begin{tabular}{lllllll} 
Pika & 19 & 0.08 & & & NA \\
Yak & 40 & 0.18 & 0.52 & 0.25 & 0.30 & 0 \\
Cow & 7 & 0.03 & 0.06 & 0.03 & 0.05 & - \\
Goat & 35 & 0.16 & 0.13 & 0.08 & 0.11 & 0 \\
Sheep & 10 & 0.04 & 0.03 & 0.02 & 0.04 & 0 \\
\hline
\end{tabular}
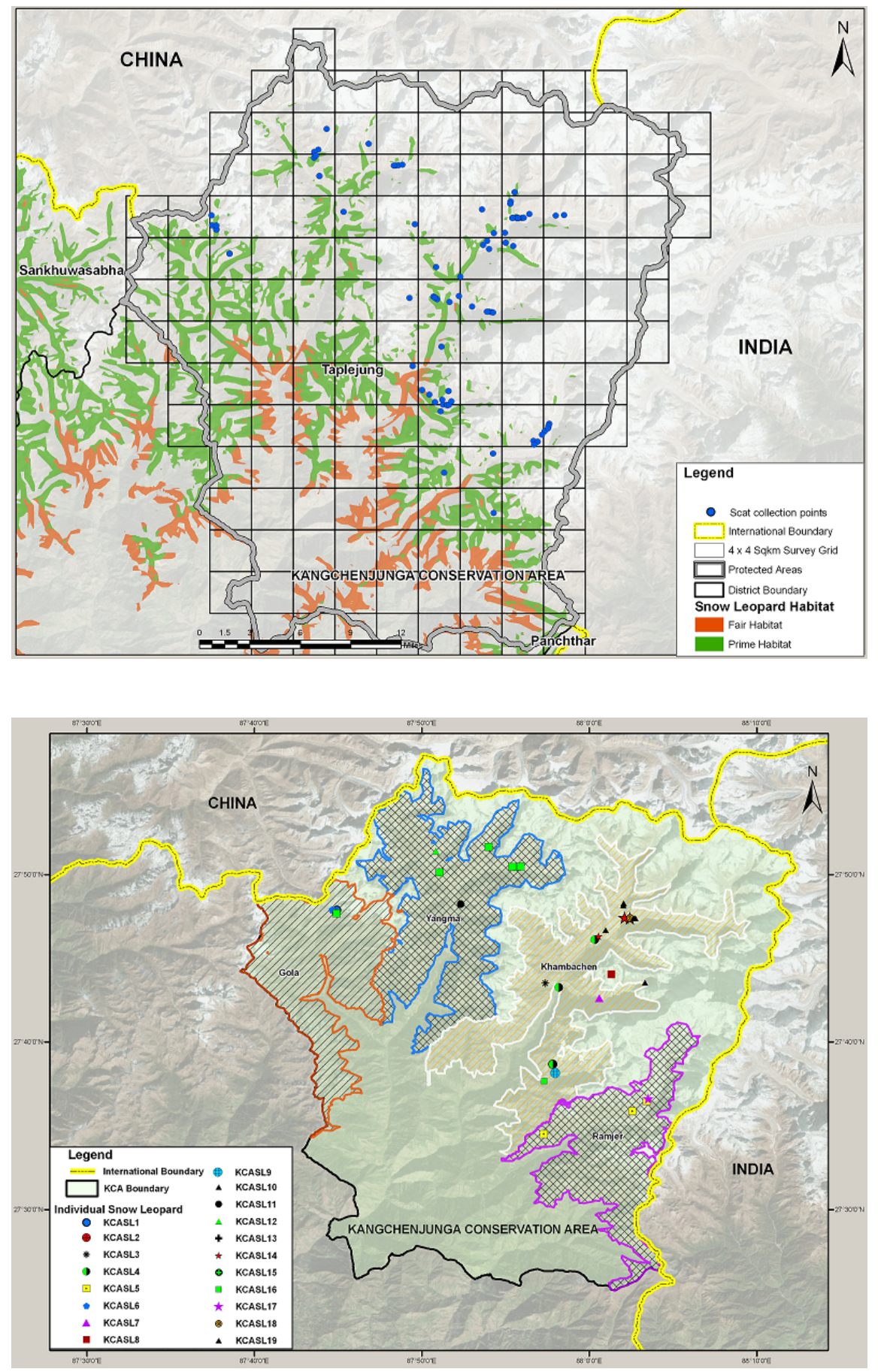